\title{
Tonic and Phasic Changes in Anteromedial Globus Pallidus Activity in Tourette Syndrome
}

Citation for published version (APA):

Israelashvili, M., Smeets, A. Y. J. M., Bronfeld, M., Zeef, D. H., Leentjens, A. F. G., van KranenMastenbroek, V., Janssen, M. L. F., Temel, Y., Ackermans, L., \& Bar-Gad, I. (2017). Tonic and Phasic Changes in Anteromedial Globus Pallidus Activity in Tourette Syndrome. Movement Disorders, 32(7), 1091-1096. https://doi.org/10.1002/mds.27043

Document status and date:

Published: 01/07/2017

DOI:

10.1002/mds.27043

Document Version:

Publisher's PDF, also known as Version of record

Document license:

Taverne

Please check the document version of this publication:

- A submitted manuscript is the version of the article upon submission and before peer-review. There can be important differences between the submitted version and the official published version of record.

People interested in the research are advised to contact the author for the final version of the publication, or visit the DOI to the publisher's website.

- The final author version and the galley proof are versions of the publication after peer review.

- The final published version features the final layout of the paper including the volume, issue and page numbers.

Link to publication

\footnotetext{
General rights rights.

- You may freely distribute the URL identifying the publication in the public portal. please follow below link for the End User Agreement:

www.umlib.nl/taverne-license

Take down policy

If you believe that this document breaches copyright please contact us at:

repository@maastrichtuniversity.nl

providing details and we will investigate your claim.
}

Copyright and moral rights for the publications made accessible in the public portal are retained by the authors and/or other copyright owners and it is a condition of accessing publications that users recognise and abide by the legal requirements associated with these

- Users may download and print one copy of any publication from the public portal for the purpose of private study or research.

- You may not further distribute the material or use it for any profit-making activity or commercial gain

If the publication is distributed under the terms of Article $25 \mathrm{fa}$ of the Dutch Copyright Act, indicated by the "Taverne" license above, 
colleagues $^{7}$ described 2 dystonia-related KMT2B missense variants that were each transmitted from a phenotypically normal parent. Future studies are required to decisively answer the questions of incomplete penetrance and variable expressivity in $K M T 2 B$-associated disease. Until then, we propose that pathogenicity should be ascribed only to those nontruncating KMT2B variants that show a clear-cut segregation pattern or were proven to be de novo.

Regarding the phenotypes, the patients presented here tended to have a later symptom onset than the previously described KMT2B-mutated individuals (mean 22.3 years, range 7-43 years; mean age of onset in the original cohorts 5.8 years, range $1-23$ years). ${ }^{6,7}$ This might be related to the milder impact of missense mutations when compared with full monoallelic loss of KMT2B as seen in most original cases. ${ }^{6,7}$ A finding of special interest is that the current cases differed from those previously reported $^{6,7}$ in that they experienced normal psychomotor development and showed no evidence of accompanying neurological or systemic complications. This raises the intriguing possibility that $K M T 2 B$ mutation should also be given consideration in the differential diagnosis of more pure, "idiopathic"-appearing generalized dystonia. Clues to KMT2B diagnosis might be early dystonia onset in the lower limbs and eventual spread to the trunk and cranio-cervical region with pronounced speech involvement. Regarding the latter, KMT2B-associated dystonia might resemble DYT-THAP1. ${ }^{3}$

We employed WES for mutation analysis, a still underevaluated tool in dystonia diagnostics. WES enables the interrogation of multiple candidate genes in a fast and cost-efficient manner, ${ }^{14}$ suggesting that this tool should be considered an appropriate test for routine diagnostic work-up of etiologically unexplained generalized dystonia. ${ }^{5}$

To conclude, our study extends the KMT2B mutational spectrum and offers further evidence for a causative role of $K M T 2 B$ rare missense variants in the pathogenesis of generalized dystonia. In the face of large numbers of rare nonsynonymous KMT2B alleles appearing in the ExAC population, the careful application of variant interpretation checklists is warranted to help distinguish pathogenic missense changes from innocuous background variation.

Acknowledgments: The authors thank all of the patients with dystonia and their family members who participated in this study.

\section{References}

1. Albanese A, Bhatia K, Bressman SB, et al. Phenomenology and classification of dystonia: a consensus update. Mov Disord 2013; 28:863-873.

2. Balint B, Bhatia KP. Dystonia: an update on phenomenology, classification, pathogenesis and treatment. Curr Opin Neurol 2014;27: 468-476.

3. Klein C. Genetics in dystonia. Parkinsonism Relat Disord 2014; 20(suppl 1):S137-S142.
4. Domingo A, Erro R, Lohmann K. Novel dystonia genes: clues on disease mechanisms and the complexities of high-throughput sequencing. Mov Disord 2016;31:471-477.

5. Zech M, Boesch S, Jochim A, et al. Clinical exome sequencing in early-onset generalized dystonia and large-scale resequencing follow-up [published online ahead of print 2016]. Mov Disord.

6. Zech M, Boesch S, Maier EM, et al. Haploinsufficiency of KMT2B, encoding the lysine-specific histone methyltransferase $2 \mathrm{~b}$, results in early-onset generalized dystonia. Am J Hum Genet 2016; 99:1377-1387.

7. Meyer E, Carss KJ, Rankin J, et al. Mutations in the histone methyltransferase gene KMT2B cause complex early-onset dystonia. Nat Genet 2017;49:223-237.

8. van Egmond ME, Kuiper A, Eggink H, et al. Dystonia in children and adolescents: a systematic review and a new diagnostic algorithm. J Neurol Neurosurg Psychiatry 2015;86:774-781.

9. Adzhubei IA, Schmidt S, Peshkin L, et al. A method and server for predicting damaging missense mutations. Nat Methods 2010;7:248-249.

10. Kircher M, Witten DM, Jain P, O'Roak BJ, Cooper GM, Shendure $\mathrm{J}$. A general framework for estimating the relative pathogenicity of human genetic variants. Nat Genet 2014;46:310-315.

11. Ansari KI, Mandal SS. Mixed lineage leukemia: roles in gene expression, hormone signaling and mRNA processing. FEBS J 2010;277:1790-1804.

12. Lek M, Karczewski KJ, Minikel EV, et al. Analysis of protein-coding genetic variation in 60,706 humans. Nature 2016;536:285-291.

13. Richards S, Aziz N, Bale S, et al. Standards and guidelines for the interpretation of sequence variants: a joint consensus recommendation of the American College of Medical Genetics and Genomics and the Association for Molecular Pathology. Genet Med 2015;17: 405-424.

14. Retterer K, Juusola J, Cho MT, et al. Clinical application of whole-exome sequencing across clinical indications. Genet Med 2016;18:696-704.

\section{Supporting Data}

Additional Supporting Information may be found in the online version of this article at the publisher's web-site.

\section{Tonic and Phasic Changes in Anteromedial Globus Pallidus Activity in Tourette Syndrome}

\author{
Michal Israelashvili, MSc, ${ }^{1}$ Anouk Y.J.M. Smeets, MD, ${ }^{2,3}$ \\ Maya Bronfeld, PhD, ${ }^{1}$ Dagmar H. Zeef, MD, PhD, ${ }^{2}$
}

${ }^{\star}$ Correspondence to: Dr. Izhar Bar-Gad, Bar-llan University, Gonda Brain Research Center, Ramat-Gan 52900, Israel. E-mail: izhar.bar-gad@ biu.ac.il

Funding agencies: This study was supported, in part, by an Israel Science Foundation (ISF) grant (743/13; to I.B.G.) and a Tourette Syndrome Association (TSA) grant (to I.B.G.).

Relevant conflicts of interest/financial disclosures: Nothing to report. Full financial disclosures and author roles may be found in the online version of this article.

Received: 12 January 2017; Revised: 20 March 2017; Accepted: 3 April 2017

Published online 29 May 2017 in Wiley Online Library (wileyonlinelibrary.com). DOI: 10.1002/mds.27043 
Albert F.G. Leentjens, MD, PhD, ${ }^{4}$

Vivianne van Kranen-Mastenbroek, MD, $\mathrm{PhD},{ }^{5}$

Marcus L.F. Janssen, MD, PhD, ${ }^{5}$ Yasin Temel, MD, PhD, ${ }^{2,3}$

Linda Ackermans, MD, PhD, ${ }^{2}$ and Izhar Bar-Gad, $\mathrm{PhD}^{1 *}$

${ }^{1}$ The Leslie \& Susan Goldschmied (Gonda) Multidisciplinary Brain Research Center, Bar-Ilan University, Ramat-Gan, Israel

${ }^{2}$ Departments of Neurosurgery ${ }^{3}$ Neuroscience ${ }^{4}$ Psychiatry and Psychology ${ }^{5}$ Neurology, Maastricht University Medical Center, Maastricht, The Netherlands

\begin{abstract}
Background: Tourette syndrome is a hyperkinetic neurodevelopmental disorder characterized by tics.

Objective: Assess the neuronal changes in the associative/limbic GP associated with Tourette syndrome.

Methods: Neurophysiological recordings were performed from the anterior (associative/limbic) GPe and GPi of 8 awake patients during DBS electrode implantation surgeries.

Results: The baseline firing rate of the neurons was low in a state-dependent manner in both segments of the GP. Tic-dependent transient rate changes were found in the activity of individual neurons of both segments around the time of the tic. Neither oscillatory activity of individual neurons nor correlations in their interactions were observed.

Conclusions: The results demonstrate the involvement of the associative/limbic pathway in the underlying pathophysiology of Tourette syndrome and point to tonic and phasic modulations of basal ganglia output as a key mechanisms underlying the abnormal state of the disorder and the expression of individual tics, respectively. (c) 2017 International Parkinson and Movement Disorder Society
\end{abstract}

Key Words: Tourette syndrome; deep brain stimulation (DBS); globus pallidus; neurophysiology; hyperkinetic disorders

Tourette syndrome (TS) is a childhood-onset neurodevelopmental disorder characterized by motor and vocal tics. ${ }^{1}$ The underlying mechanism of TS is still largely unknown; however, multiple lines of evidence have linked it to malfunctions in the cortico-basal ganglia pathway ${ }^{2,3}$ and specifically to reduced inhibition within the striatum, the primary input nucleus of the basal ganglia $(\mathrm{BG}))^{3-5}$ The striatum controls the output of the BG through two pathways: the direct pathway to the output nucleus of the BG, the globus pallidus internus (GPi), and the indirect pathway to the GPi through the globus pallidus externus (GPe). ${ }^{6,7}$ These pathways are further subdivided into functional pathways that convey motor information primarily to the posteroventral GPi (pGPi) and associative/limbic information to the anteromedial GPi (aGPi). ${ }^{8}$

Currently, there are scant neurophysiological data from TS patients. Extracellular neuronal recordings performed during pallidotomy surgery revealed a decreased overall firing rate in the pGPi of TS patients complemented by phasic firing rate changes around the time of the tic. ${ }^{9}$ DBS targeting the aGPi in TS patients provides a rare opportunity to directly observe neuronal activity in the associative/limbic domains of the BG. The current study focuses on linking the activity of GPe/GPi neurons in these domains with TS pathophysiology.

\section{Patients and Methods}

The data were collected from 8 patients, aged 19 to 55 years $(37 \pm 14$, mean \pm standard deviation [SD]) who underwent surgery for the bilateral implantation of DBS electrodes in the aGPi, as treatment for TS (Supplementary Table S1). Patients were selected using strict inclusion and exclusion criteria according to the European guidelines for $\mathrm{TS}^{10,11}$ (see also the Supplementary Material). Full clinical details and surgery outcomes are described in previous works. ${ }^{2,13}$ The surgery was performed under local anesthesia and sedation (Supplementary Table S1) while the patients were awake. The target for electrode implantation (aGPi) was defined as $12 \mathrm{~mm}$ lateral, 6 to $9 \mathrm{~mm}$ anterior, and 0 to $3 \mathrm{~mm}$ superior to the midcommisural point. Up to five microelectrodes were used to record the neuronal activity along the trajectory for mapping purposes. Recording took place from $10 \mathrm{~mm}$ above target to $4 \mathrm{~mm}$ beneath target in $0.5-$ to $1.0-\mathrm{mm}$ steps. The electrode signal was bandpass filtered $(160-5,000 \mathrm{~Hz})$, and sampled at 20 or $25 \mathrm{kHz}$ (V3.15; inomed Medizintechnik GmbH, Emmendingen, Germany). Movement during neuronal recordings was monitored by simultaneous electromyogram (EMG) recordings, sampled at $2 \mathrm{kHz}$. EMG recordings were available only in three surgeries (patients $\mathrm{V}, \mathrm{K}$, and $\mathrm{O}$ ). In addition, a simultaneous video recording of the face was available in one surgery (patient K).

A full description of the data preprocessing and analysis can be found in the Supplementary Material.

\section{Results \\ Firing Rate and Pattern}

A total of 235 single neurons were recorded from 8 awake TS patients during neurophysiological mapping for placement of DBS electrodes in the aGPi. The neurons were identified as GPe $(n=77)$ or GPi $(\mathrm{n}=158)$ neurons based on their location and trajectory history, including border cells and low background activity between the GPe and GPi (Fig. 1). The firing rates were $48.25 \pm 3.4$ and $50.9 \pm 2.6$ spikes/s 
A

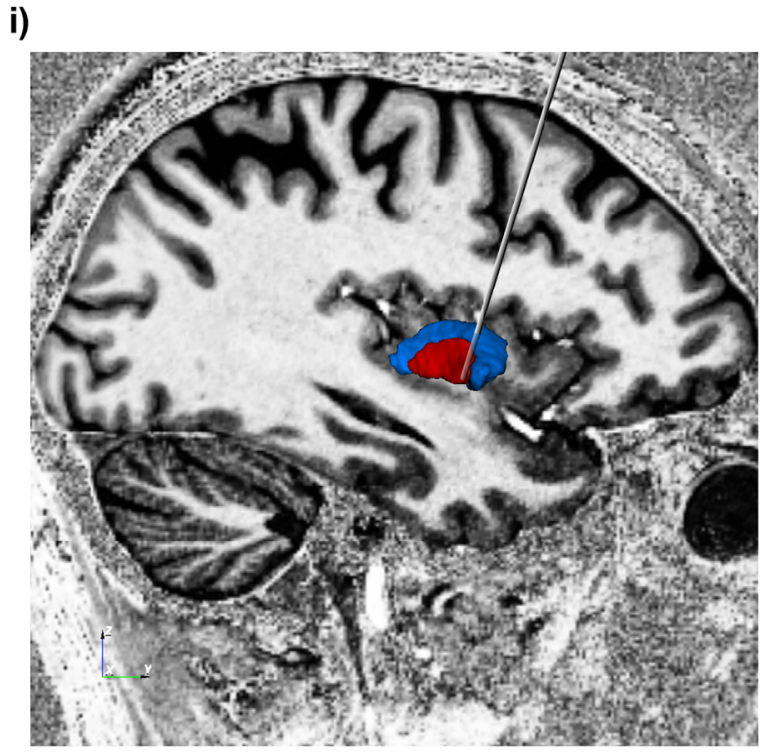

ii)

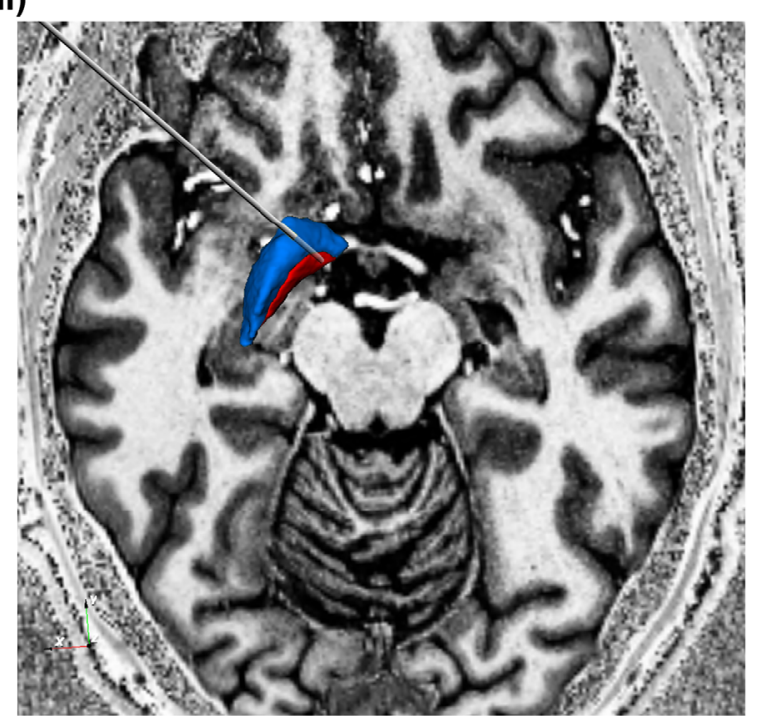

B

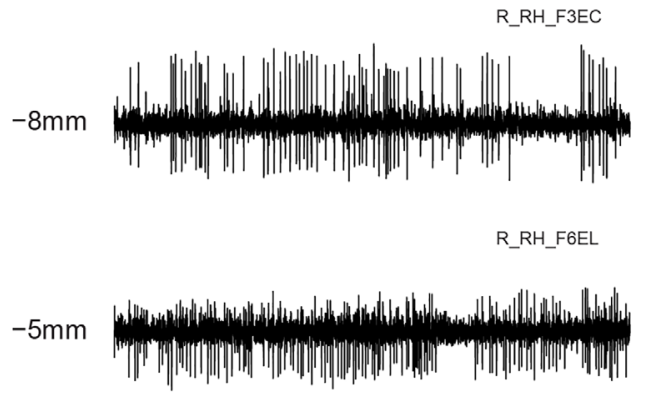

$\mathrm{GPe}$

GPi

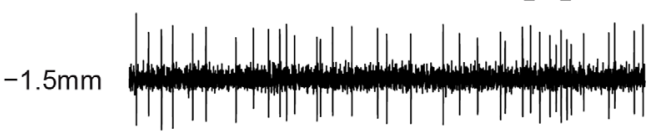

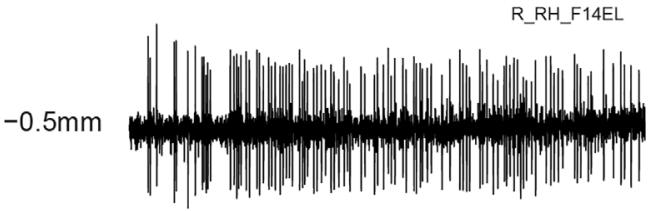

R_RH_F15EA
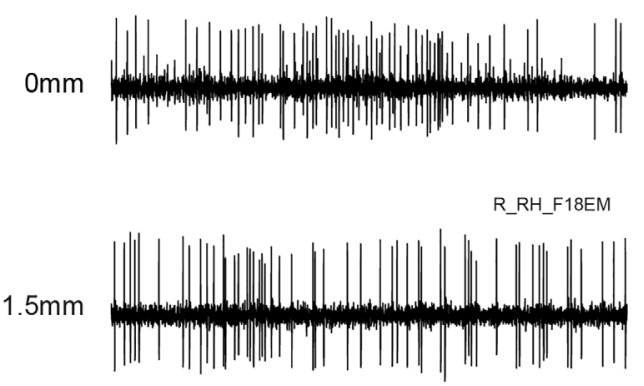

R_RH_F20EL

$2.5 \mathrm{~mm}$

FIG. 1. Recording track. (A) An example of the recording electrode track overlaid on (i) sagittal and (ii) axial MRI for purposes of illustration. Blue, $\mathrm{GPe}$; red, GPi. (B) Examples of neurons recorded from several locations along one track. The electrode depth is shown in relation to the location of the stimulation electrode implantation site $(0 \mathrm{~mm})$.

(mean \pm standard error of the mean) for GPe and GPi neurons, respectively. The firing rate distributions were positively skewed, indicating that the firing rate of most neurons was even lower, with a small subpopulation of high-frequency discharge neurons (Supplementary Fig. S1). Although the firing rates were similar between GPe and GPi neurons, the firing patterns of the neurons in each nucleus were different. Both the coefficient of variation $(\mathrm{CV})$ and the Fano factor $(\mathrm{FF})$ were higher in GPe neurons, in line with their typical pauses, as compared to GPi neurons which presented Poisson-like values of $\mathrm{CV}$ and $\mathrm{FF}$
( 1; Supplementary Fig. S1). Three of the patients received Propofol during the surgery, which was halted or lowered 15 minutes before the recordings. The neuronal activity in these patients was not statistically different from the activity in the other patients (Supplementary Fig. S2).

Different pathologies of the BG, most notably Parkinson's disease (PD), are associated with enhanced oscillatory activity. We found no significant oscillations in the spike trains of neither GPe nor GPi neurons using power spectral estimation methods (Supplementary Material). 
A
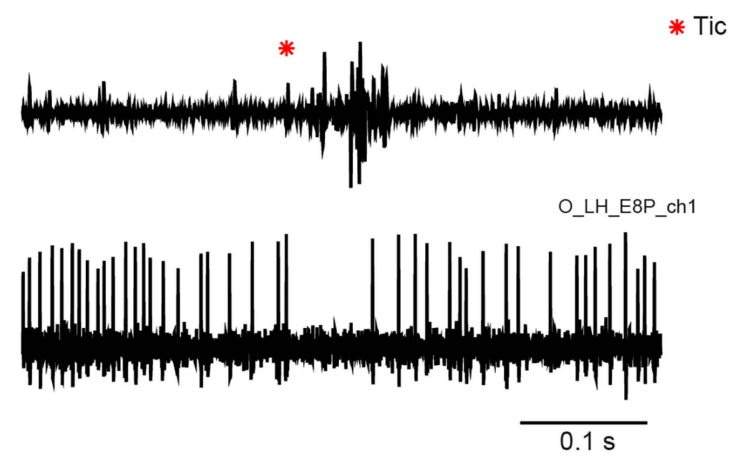

B

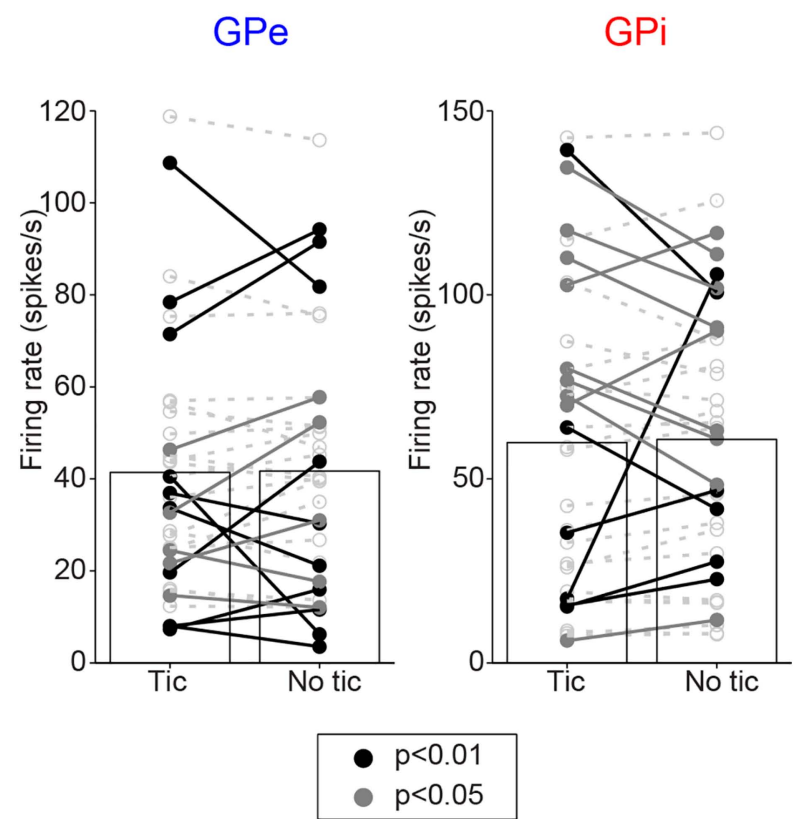

FIG. 2. Tic-related changes in firing rate. (A) An example of simultaneously recorded EMG (top) and GPe neuron (bottom) around the time of a tic. $(B, C)$ Mean firing rate around tic time $(0.5$ seconds pre tic onset $->1$ second post tic onset) for $\mathrm{GPe}(\mathrm{B})$ and $\mathrm{GPi}(\mathrm{C})$ neurons (calculated on data from 3 patients). Each dot represents one neuron. Colored dots represent neurons that displayed significant firing rate changes around the time of the tics. The bar plot represents the mean firing rate of all neurons in each period (tics vs. no tics). [Color figure can be viewed at wileyonlinelibrary.com]

\section{Neuronal Interactions}

Neuronal activity in the GPe/GPi of the normal nonhuman primate is uncorrelated. ${ }^{14,15}$ However, positive correlations between these neurons appear in PD patients ${ }^{16,17}$ and in the primate model of the disorder. ${ }^{15}$ To examine whether changes in firing synchrony play a role in the pathophysiology of tics, we examined the correlation in spike firing between simultaneously recorded neurons. Cross-correlation functions were calculated between the spike trains of 63 pairs (GPe, 18; $\mathrm{GPi}, 45$ ) of simultaneously recorded single neurons. The activity of the neurons was found to be uncorrelated as none of the cross-correlation functions had significant peaks. We calculated the Pearson product-moment correlation coefficient between the spike trains of each pair of neurons. The average correlation coefficient for the whole population of pairs was zero with narrow margins $(0.00 \pm 0.03$, mean $\pm S D)$. Coherence was used to study the degree of neuronal interaction as a function of frequency. Mean coherence between all simultaneously recorded pairs was flat, with no significant peak at any frequency (Supplementary Fig. S3).

\section{Tic-Related Changes in Neuronal Activity}

The expression of tics was associated with altered neuronal activity throughout the GP (Fig. 2A). Tic times were identified using EMG recordings from 3 patients (patients $\mathrm{V}, \mathrm{O}$, and $\mathrm{K}$; patient $\mathrm{K}$ in addition had a video recording). Mean firing rate of each neuron during 1.5 seconds $(-0.5$ second $\rightarrow+1$ second $)$ around tics onset was compared to the mean firing rate of the neuron during the rest of the time (using 100 -ms time windows). A large fraction $(44.1 \% ; 15$ of 34) of the GPe neurons significantly changed their firing rate around the time of the tic (two-sample $t$ test; 10 of 15 with $P<0.01$ and 5 of 15 with $P<0.05$; Fig. 2B). Similarly, $41.7 \%$ (15 of 36 ) of the GPi neurons significantly changed their firing rate around the time of the tic ( 6 of 15 with $P<0.01$ and 9 of 15 with $P<0.05$; Fig. 2C). In both nuclei, half of the responding neurons (8 of $15 \mathrm{GPe}, 7$ of $15 \mathrm{GPi}$ ) displayed a decrease in activity around the time of the tic. The fraction of neurons displaying tic-related activity was significantly higher than expected by the distribution of changes around random time events $(\mathrm{z}$ score: GPe, $P<0.05$; GPi, $P<0.01)$. In contrast to the significant firing-rate changes of individual neurons, mean response of GPe as well as of GPi population to tics was not significantly different from baseline activity (paired-sample $t$ test: $P>0.05$; Fig. 2B,C, bar plot). Thus, despite phasic tic-related changes in the firing rate of individual neurons, mean firing rate of both nuclei did not phasically change during tic occurrence.

\section{Discussion}

In this study, we examined neuronal activity in the anterior (associative/limbic) GPe and GPi in TS patients. The baseline firing rate was low and the firing rate distribution of the neurons was skewed. In addition to the tonic reduction in the firing rates, a large fraction of the neurons displayed phasic ticdependent changes. These changes included transient increases and decreases in activity in both segments of the GP. In contrast to other BG-related disorders, oscillatory activity of individual neurons as well as abnormal synchronization between neurons were not observed.

No studies of the associative/limbic (anterior) GPi or any part of GPe tonic activity during TS have been previously conducted. Tonic activity changes in the motor (posterior) GPi during TS have been partially addressed 
in previous studies of anesthetized ${ }^{18}$ and awake ${ }^{9}$ patients undergoing a mapping procedure. Our results are in line with both studies, which found a rate decrease in the GPi compared to rates recorded in PD patients ${ }^{19}$ or normal nonhuman primates. ${ }^{15}$ Interestingly, the reduced firing rates that we observed in the GPe are comparable to those previously observed in awake patients suffering from other hyperkinetic disorders, such as dystonia ${ }^{18,20-23}$ and hemiballismus. ${ }^{24}$

Functional models of hyperkinetic movement disorders have tended to focus solely on the existence of abnormalities in the motor circuits of the BG. Here, we found changes in the activity of the anterior (associative/limbic) domains of both segments of the GP resembling those observed in the motor domain. ${ }^{9}$ This points to a clear functional interaction between the motor and associative/limbic circuits within the corticobasal ganglia loop, which is consistent with the symptomatology of TS that links limbic, for example, psychiatric comorbidities, and motor, for example, tic properties. ${ }^{25,26}$

Hyperkinetic disorders in general, and TS in particular, are hypothesized to be associated with enhanced activity of the direct pathway and reduced activity of the indirect pathway, which together leads to overactivation of the cortex. ${ }^{6,7}$ In line with this assumption, imaging studies have found abnormal activity in the GP and enhanced excitation of the direct pathway. ${ }^{27-29}$ Our results support this assumption in that the GPi neurons displayed reduced activity. However, the GPe baseline, tonic, activity was also reduced, contradicting the current perception of the indirect pathway involvement in hyperkinetic disorders. ${ }^{6,7}$ Interestingly, this comodulation of both segments of the GP is not unique to TS, but has also been observed in other hyperkinetic disorders such as dystonia ${ }^{20,21}$ and hemiballismus. ${ }^{24}$ The reduced activity in both segments can be explained by more recent theoretical models ${ }^{30,31}$ and experimental data from animal models ${ }^{32,33}$ that point to striatal disinhibition as a key factor driving the appearance of tics. This disinhibition affecting striatal projection neurons that contributes to both the direct and indirect pathways is thus expected to exert increased inhibition on both the GPe and GPi by driving their firing rates down, which is consistent with our findings. The mixture of phasic responses around the time of the tic indicates that the neurons within each nuclei form a heterogenic network, as shown in previous findings on animal models of the disorder. ${ }^{32,33}$

Our results support and extend theoretical, clinical, and experimental data suggesting tonic and phasic changes in neuronal activity throughout the BG during TS. However, our results are unique in demonstrating that these changes affect not only motor pathways, but also associative/limbic pathways, thus reflecting the complexity of the disorder. The departure of our findings from the classic perception of hyperkinetic disorders hence calls for the development of a more comprehensive model of BG functionality linking the activity in different domains of the BG in general and during hyperkinetic disorders in particular.

Acknowledgments: We thank K. Belelovsky and L. Warhaftig for technical assistance.

\section{References}

1. American Psychiatric Association. DSM-5. San Antonio, TX: The Psychological Association; 2013.

2. Singer HS, Minzer K. Neurobiology of Tourette's syndrome: concepts of neuroanatomic localization and neurochemical abnormalities. Brain Dev 2003;25(Suppl 1):S70-S84.

3. Kalanithi PS, Zheng W, Kataoka Y, et al. Altered parvalbuminpositive neuron distribution in basal ganglia of individuals with Tourette syndrome. Proc Natl Acad Sci U S A 2005;102:1330713312.

4. Kataoka Y, Kalanithi PS, Grantz H, et al. Decreased number of parvalbumin and cholinergic interneurons in the striatum of individuals with Tourette syndrome. J Comp Neurol 2010;518:277291.

5. Peterson BS, Thomas P, Kane MJ, et al. Basal ganglia volumes in patients with Gilles de la Tourette syndrome. Arch Gen Psychiatry 2003;60:415-424.

6. Albin RL, Young AB, Penney JB. The functional anatomy of basal ganglia disorders. Trends Neurosci 1989;12:366-375.

7. DeLong MR. Primate models of movement disorders of basal ganglia origin. Trends Neurosci 1990;13:281-285.

8. Alexander GE, DeLong MR, Strick PL. Parallel organization of functionally segregated circuits linking basal ganglia and cortex. Annu Rev Neurosci 1986;9:357-381.

9. Zhuang P, Hallett M, Zhang X, Li J, Zhang Y, Li Y. Neuronal activity in the globus pallidus internus in patients with tics. J Neurol Neurosurg Psychiatry 2009;80:1075-1081.

10. Müller-Vahl KR, Cath DC, Cavanna AE, et al. European clinical guidelines for Tourette syndrome and other tic disorders. Part IV: deep brain stimulation. Eur child Adolesc psychiatry. 2011;20:209217.

11. Schrock LE, Mink JW, Woods DW, et al. Tourette syndrome deep brain stimulation: a review and updated recommendations. Mov Disord 2015;30:448-471.

12. Smeets AY, Duits A, Plantinga B, et al. Deep brain stimulation of the internal globus pallidus in refractory Tourette Syndrome. Clin Neurol Neurosurg 2016;142:54-59.

13. Ackermans L, Duits A, van der Linden C, Tijssen M, Schruers K, Temel Y, et al. Double-blind clinical trial of thalamic stimulation in patients with Tourette syndrome. Brain 2011;134:832-844.

14. Nini A, Feingold A, Slovin H, Bergman H. Neurons in the globus pallidus do not show correlated activity in the normal monkey, but phase-locked oscillations appear in the MPTP model of parkinsonism. J Neurophysiol 1995;74:1800-1805.

15. Raz A, Vaadia E, Bergman H. Firing patterns and correlations of spontaneous discharge of pallidal neurons in the normal and the tremulous 1-methyl-4-phenyl-1,2,3,6-tetrahydropyridine vervet model of parkinsonism. J Neurosci 2000;20:8559-8571.

16. Hurtado JM, Gray CM, Tamas LB, Sigvardt KA. Dynamics of tremor-related oscillations in the human globus pallidus: a single case study. Proc Natl Acad Sci U S A 1999;96:1674-1679.

17. Levy R, Hutchison WD, Lozano AM, Dostrovsky JO. Synchronized neuronal discharge in the basal ganglia of parkinsonian patients is limited to oscillatory activity. J Neurosci 2002;22:28552861.

18. Alam M, Schwabe K, Lütjens G, et al. Comparative characterization of single cell activity in the globus pallidus internus of patients with dystonia or Tourette syndrome. J Neural Transm 2015;122: 687-699.

19. Hutchison WD, Lozano AM, Davis KD, Saint-Cyr JA, Lang AE, Dostrovsky JO. Differential neuronal activity in segments of globus 
pallidus in Parkinson's disease patients. Neuroreport 1994;5:15331537.

20. Starr P a, Rau GM, Davis V, et al. Spontaneous pallidal neuronal activity in human dystonia: comparison with Parkinson's disease and normal macaque. J Neurophysiol 2005;93:3165-3176.

21. Sanghera MK, Grossman RG, Kalhorn CG, Hamilton WJ, Ondo WG, Jankovic J. Basal ganglia neuronal discharge in primary and secondary dystonia in patients undergoing pallidotomy. Neurosurgery 2003;52:1358-1370.

22. Alam M, Sanghera MK, Schwabe K, et al. Globus pallidus internus neuronal activity: a comparative study of linear and non-linear features in patients with dystonia or Parkinson's disease. J Neural Transm (Vienna). 2016;123:231-240.

23. Zhuang P, Li Y, Hallett M. Neuronal activity in the basal ganglia and thalamus in patients with dystonia. Clin Neurophysiol 2004; 115:2542-2557.

24. Vitek JL, Chockkan V, Zhang JY, et al. Neuronal activity in the basal ganglia in patients with generalized dystonia and hemiballismus. Ann Neurol 1999;46:22-35.

25. Yael D, Vinner E, Bar-Gad I. Pathophysiology of tic disorders. Mov Disord 2015;30:1171-1178.

26. Israelashvili M, Loewenstern Y, Bar-Gad I. Abnormal neuronal activity in Tourette syndrome and its modulation using deep brain stimulation. J Neurophysiol 2015;114:6-20.

27. Peterson BS, Skudlarski P, Anderson AW, et al. A functional magnetic resonance imaging study of tic suppression in Tourette syndrome. Arch Gen Psychiatry 1998;55:326-333.

28. Baym CL, Corbett BA, Wright SB, Bunge SA. Neural correlates of tic severity and cognitive control in children with Tourette syndrome. Brain 2008;131:165-179.

29. Worbe Y, Malherbe C, Hartmann A, et al. Functional immaturity of cortico-basal ganglia networks in Gilles de la Tourette syndrome. Brain 2012;135:1937-1946.

30. Mink JW. Basal ganglia dysfunction in Tourette's syndrome: a new hypothesis. Pediatr Neurol 2001;25:190-198.

31. Albin RL, Mink JW. Recent advances in Tourette syndrome research. Trends Neurosci 2006;29:175-182.

32. McCairn KW, Bronfeld M, Belelovsky K, Bar-Gad I. The neurophysiological correlates of motor tics following focal striatal disinhibition. Brain 2009;132:2125-2138.

33. Israelashvili M, Bar-Gad I. Corticostriatal divergent function in determining the temporal and spatial properties of motor tics. J Neurosci 2015;35:16340-16351.

\section{Supporting Data}

Additional Supporting Information may be found in the online version of this article

\section{Patient-Reported Outcomes in Huntington's Disease: Quality of Life in Neurological Disorders (Neuro-QoL) and Huntington's Disease Health-Related Quality of Life (HDQLIFE) Physical Function Measures}

Noelle E. Carlozzi, PhD, ${ }^{1 *}$ Rebecca E. Ready, PhD, ${ }^{2}$ Samuel Frank, MD, ${ }^{3}$ David Cella, PhD, ${ }^{4,5}$

Elizabeth A. Hahn, MS, ${ }^{5}$ Siera M. Goodnight, MPH, ${ }^{1}$

Stephen G. Schilling, PhD, ${ }^{1,6}$ Nicholas R. Boileau, BA, ${ }^{1}$ and Praveen Dayalu, $\mathrm{MD}^{7}$
${ }^{1}$ Department of Physical Medicine and Rehabilitation, University of Michigan, Ann Arbor, Michigan, USA ${ }^{2}$ Department of Psychological and Brain Sciences, University of Massachusetts, Amherst, Massachusetts, USA ${ }^{3}$ Beth Israel Deaconess Medical Center, Boston, Massachusetts, USA ${ }^{4}$ Institute for Health Services Research \& Policy Studies, Feinberg School of Medicine, Northwestern University, Chicago, Illinois, USA ${ }^{5}$ Department of Medical Social Sciences, Northwestern University, Chicago, Illinois, USA ${ }^{6}$ Institute for Social Research, University of Michigan, Ann Arbor, Michigan, USA ${ }^{7}$ Department of Neurology, University of Michigan, Ann Arbor, Michigan, USA

\section{ABSTRACT}

Background: There is a need for patient-reported outcome measures that capture the impact that motor impairments have on health-related quality of life in individuals with Huntington's disease.

Objectives: The objectives of this study were to establish the reliability and validity of new physical functioning patient-reported outcome measures in Huntington's disease.

Methods: A total of 510 individuals with Huntington's disease completed 2 Quality of Life in Neurological Disorders (Lower Extremity Function and Upper Extremity Function) and 3 Huntington's Disease HealthRelated Quality of Life (Chorea, Speech Difficulties, and Swallowing Difficulties) measures. Clinician-rated and generic self-report measures were also administered.

Results: Reliabilities for the new patient reported physical functioning measures were excellent (all Cronbach's $\alpha>$.92). Convergent, discriminant validity and known group validity was supported.

Conclusions: The results provide psychometric support for new patient-reported physical functioning measures and the fact that these measures can be used as clinically meaningful endpoints in Huntington's disease research and clinical practice. (C) 2017 International Parkinson and Movement Disorder Society

Key Words: Neuro-QoL; HDQLIFE; Huntington's disease; physical functioning; chorea; motor symptoms; health-related quality of life; patient-reported outcome (PRO)

Huntington's disease (HD) is a progressive neurodegenerative disorder that causes profound cognitive, behavioral, and motor declines. The motor

*Corresponding author: Dr. Noelle E. Carlozzi, University of Michigan, Department of Physical Medicine \& Rehabilitation, North Campus Research Complex, 2800 Plymouth Road, Building NCRC B14, Room G216, Ann Arbor, Ml 48109-2800; carlozzi@med.umich.edu

Relevant conflicts of interests/financial disclosures: Nothing to report.

Received: 11 November 2016; Revised: 17 April 2017; Accepted: 19 April 2017

Published online 27 May 2017 in Wiley Online Library (wileyonlinelibrary.com). DOI: 10.1002/mds.27046 